\title{
Impact of Training Deep Vocabulary Learning Strategies on Vocabulary Retention of Iranian EFL Learners
}

\author{
Seyed Javad Es-hagi Sardroud \\ Tabriz Islamic Azad University, Iran \\ Tel: (+98)04113396002 E-mail: eshagiir2008@gmail.com
}

Received: 29-01-2013

doi:10.7575/aiac.ijalel.v.2n.3p.75
Accepted: 19-03-2013

Published: 01-05-2013

URL: http://dx.doi.org/10.7575/aiac.ijalel.v.2n.3p.75

\begin{abstract}
Considering the overall tendency of foreign language learners to use mechanical strategies of rote rehearsal in vocabulary learning and their resistance towards use of 'deep' vocabulary learning strategies, namely contextual guessing, Keyword Method, metacognitive strategy, and semantic mapping, this study intended (a) to explore what impact the instruction of these deep strategies, on vocabulary retention of 32 post-intermediate adult EFL Iranian learners, (b) to determine how the variable of gender influences the vocabulary retention of students after receiving training in these strategies. To this end, on the basis of a strategy-based model of instruction-CALLA (Chamot \& O'Malley, 1994), the experimental group received training in using 'deep' vocabulary learning strategies while the control group received only the common method of vocabulary teaching. After the treatment, following factorial design, the performance of the participants in the teacher-made vocabulary test as posttest was analyzed statistically. The results indicated higher vocabulary retention for the experimental group, and it was revealed that female students were more receptive to strategy training. This study provides evidence for confirmation of 'depth of processing' hypothesis and the emerging theory about the impact of gender on effective strategy teaching and use, and it recommends incorporation of teaching these 'deep' strategies of vocabulary learning into EFL classrooms.
\end{abstract}

Keywords: contextual guessing, 'deep' vocabulary learning strategies, Keyword Method, metacognitive strategy, semantic mapping

\section{Introduction}

In teaching a foreign language, one of the main problems teachers encounter is how to help students commit a massive amount of foreign words to memory. It is frequently observed that the first and easiest strategy student pick up and use naturally is simply repeating new words until they can be recognized or memorized. As Nielsen (2003) reports, "research that has attempted to investigate which vocabulary strategies are most commonly used by second language learners has revealed that more mechanical strategies are often favored over more complex ones (p. 4)". On the hand, according to Oxford and Nyikos (1989), most of the successful learners use some strategies other than rote rehearsal strategies, and Oxford (1994) believes that the other learners should be aware of different vocabulary learning strategies, used by good learners, and encourages teachers to teach these strategies. In this respect, studies have indicated that strategy training is frequently successful, but this has not been consistently confirmed (O'Malley \& Chamot, 1990; Gu, 2003).

\section{1 'deep' vocabulary learning strategies}

AS Segler (2001) suggests, Depth of Processing Hypothesis (henceforth, DOPH) can provide a 'potential framework' for comparing different strategies of (explicit) vocabulary learning. This hypothesis, proposed by Craik and Lockhart (1972), postulates that deeper analysis of a stimulus (with 'depth' referring to a greater degree of semantic involvement) leads to better long-term memory retention. when applied to vocabulary acquisition, this hypothesis, as Ellis (1995) states, "holds that shallow processing like oral rehearsal does not lead to long-term retention of words but that deep processing, whereby semantic associations are accessed and elaborated, does" (p. 409) Based on the DOP variable, vocabulary learning is viewed as a process of related sub-tasks. Out of these sub-tasks of vocabulary learning process, some tasks have been identified as tasks, which require deep processing and demand 'deep' strategy use (Segler, 2001). 'Deep' processing strategies, as Ellis (1995) mentions, involves; imagery mediation, semantic mediation and metalinguistic strategies for inferencing. The relevant sub-strategies of these 'deep' vocabulary-learning strategies, identified in Schmitt's (1997) taxonomy of vocabulary learning strategies, are Keyword Method, contextual guessing, metacognitive strategies, and semantic mapping.

\subsection{Research into 'deep' vocabulary learning strategies}

According to research literature, 'deep' processing strategies have been found more effective in vocabulary retention than rote repetition strategies (see Cohen \& Aphek, 1980; O’Malley et al., 1990; Schmitt, 1997). On the other hand, Kudo (1999) showed that among Japanese EFL students cognitively demanding vocabulary learning strategies were 
unpopular whereas cognitively shallower ones such as verbal repetition were popular. In addition, regarding the outcome of teaching 'deep' strategies of vocabulary learning, there have been few but varied results.

According to Nielson (2003), Keyword method remains largely unpopular with both teachers and learners because of the effort needed in memorizing words via this strategy. Van Hall and Mahn (1997, cited in Hunt \& Beglar, 2005, p. 21) indicate that a greater degree of forgetting is associated with the keyword mnemonic strategy relative to a nonmnemonic strategy (e.g., rote learning). In addition, its effective is reported to be largely dependent on the proficiency level of L2 learners (Cohen et al.,1980). As for the contextual guessing strategy, there are some reservations about how well students can deal with context on their own because some EFL/ESL studies suggest that learners are often unable to guess the meaning of an unknown word from a text (Haynes, 1993; Kelly, 1990, cited in Coady, 1997, p. 226). For the instruction of metaconitive strategy, O'Malley, Chamot, Kupper, and Russo (1985) revealed that high-achieving students reported greater use of metacognitive strategies. They concluded that the more successful students are probably able to use greater metacognitive control over their learning. On the other hand, there have been some studies that show the effectiveness of training metacognitive and semantic map strategies on the vocabulary learning of EFL students (see Rasekh \& Rabjbari, 2003; Brown \& Perry,1996; Zeid,1995 )

\subsection{Statement of the problem and purpose of the study}

In attempting to introduce vocabulary-learning-strategy training into a second language classroom, research alerts us to some potential pitfalls such as: there may be some resistance to application of those vocabulary learning strategies, which involve deeper elaboration, because of the cognitive effort required in memorizing words in this manner (Nielsen (2003).

Therefore, it is possible that in spite of training in using 'deep' vocabulary learning strategies, EFL learners may still tend to turn to using those 'shallow' vocabulary-learning strategies, which require less mental effort in vocabulary learning process. Moreover, the effectiveness of strategy training may vary among male and female students because of the impact of gender variable which have been reported to influence strategy training (Chamot and O'Malley,1994). Therefore, in the relevant research the uncertainty remains as to first; whether teaching deep vocabulary learning strategies can enhance vocabulary retention of adult EFL learners; second, whether this instruction affects the vocabulary retention of male and female learners differently. The purpose of this study was to shed light on this uncertainty by exploring any change in vocabulary retention of EFL learners, in general, and any difference between male and female students' vocabulary retention, in particular, after receiving training in 'deep' vocabulary learning strategies.

\subsection{Research Questions}

Regarding the purpose of the study, the following research questions were raised:

1. Is there any significant relationship between the explicit instruction of a 'deep' vocabulary learning strategies and improvement of EFL learners' vocabulary retention?

2. Is there any significant difference between vocabulary retention of female and male Iranian EFL learners after their being exposed to the explicit instruction of 'deep' vocabulary learning strategies?

As such, on the basis of DOP hypothesis, it was expected that vocabulary retention of the students would improve when exposed to training in 'deep' vocabulary learning strategy. To meet the requirements of the scientific studies and increase the validity of the experiment, two null hypothesizes were suggested to claim that: first, raining 'deep' vocabulary strategies does not have any impact on improving the vocabulary retention of Iranian EFL students; second, there would be no significant difference in vocabulary retention of male and female Iranian EFL students because of gender variable.

\section{Methodology}

The study was designed to focus on the implementation of 'deep' vocabulary learning strategy instruction in an EFL preTOEFL classroom following Chamot et al. (1994) model of Cognitive Academic Language Learning Approach (CALLA). The process of instruction in CALLA is based on the assertion that strategies being as "declarative knowledge that can become proceduralized with practice and, like complex cognitive skills, proceed through the cognitive, associative and autonomous stages of learning" (Chamot et al, 1994, p. 372). The underlying assumption behind choosing this model was derived from the premise that all vocabulary learning strategies are a sub-class of language learning strategies (see Schmitt, 1997, for his taxonomy of vocabulary learning strategies)

\subsection{Participants}

The participants in this study were 32 EFL Iranian students, aged 18 to 25, at post-intermediate level of language proficiency, taking part in Pre-TOEFL course of an EFL Institute in Tabriz, Iran. Because the researcher accessed only two classes of the same level of proficiency, using intact group design was inevitable, thereby using the availability sampling, in which the participants were randomly were assigned into 2 mixed classes, one as control group and the other class as experimental group

\subsection{Instrumentation}

At the pursuit of the research intention, the following instruments were used: 1) Barron's TOEFL (version 1996) was used as a standardized measure to check the homogeneity of the participants in terms of English language proficiency. 2) A teacher-made 60 item multiple-choice vocabulary test as pre-test which was developed using TOEFL WORD flash 
(Milada, 2005) in order to eliminate the words they already know, and select a set of English lexical words unknown to them. 3) A 40 item multiple-choice test of vocabulary achievement (VAT) as post-test which was developed out of the pre-test.

\subsection{Procedure}

A week before treatment, all of the participants were given the pre-test and Barron's TOEFL test (version 1996). Both the experimental and control groups attended the 40-hour Pre-TOEFL course in which 20 minutes per class were allocated to teaching vocabulary book, TOEFL WORD flash (Milada, 2005). Both groups received the common practice of teaching vocabulary based on the procedures suggested in TOEFL WORD flash. As treatment phase, only the experimental group was subjected to the explicit instruction of 'deep' vocabulary learning strategies, based on fivephase recursive cycle of instruction in CALLA approach (Chamot et.al O'Malley, 1994). First session of treatment the relevant handouts including both the implementation steps and samples were distributed to the participants of experimental group to familiarize them with the strategies (Preparation phrase). The following four sessions, the researcher as teacher one by one modeled application of the strategies using the new vocabularies in Milada's (2005) book: TOEFL WORD flash (Presentation phase). Later on, students were given enough opportunity of practicing the 'deep' strategies by drawing and personalizing their own works (practice). At the evaluation phase the participant's personal semantic maps, keywords in L1, reasons or clues behind their guessing of meaning, and their plans and learning logs to learn the new vocabularies in the taught book were discussed and modified. As final phase of treatment; expansion phase, student were encouraged to: a) apply these deep strategies to new contexts out of the book, and b) devise their own individual combination and interpretations of the taught 'deep' strategies.

Here, only a short account of how the participants applied the taught strategies in the classroom is presented along with the relevant samples. Regarding Keyword method, at first students were encouraged to find keywords from their mother tongue that sounded similar to the given new English words either phonologically or orthographically, and then they were required to translate the new words. As the last stage the participants tried to associate the keywords with their L1 translation through an interactive visual image. This can be shown explicitly in the following sample keywords:

Example 1. Boom (FL word) - بوم (keyword) - رشدو بيشرفت سريع (Persian translation) :

\section{Acoustic link: /Bu:m/ Imagery link:}

Example 2. Insipid (FL word) - بي مزه - (keyword) بوم: بين (Persian translation)

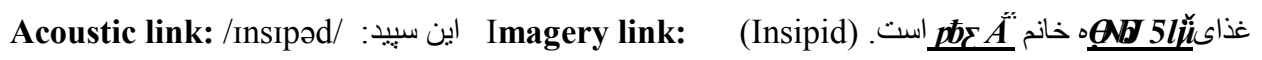

As for semantic mapping, the students were given the central topics of the book such as kindness, fear, courage, tastes, movement, etc to find the relevant new words in the book and generate examples as many as possible to put in subcategories and connect them to the central concepts. Here is one modified sample of semantic mapping prepared by one of the participant students:

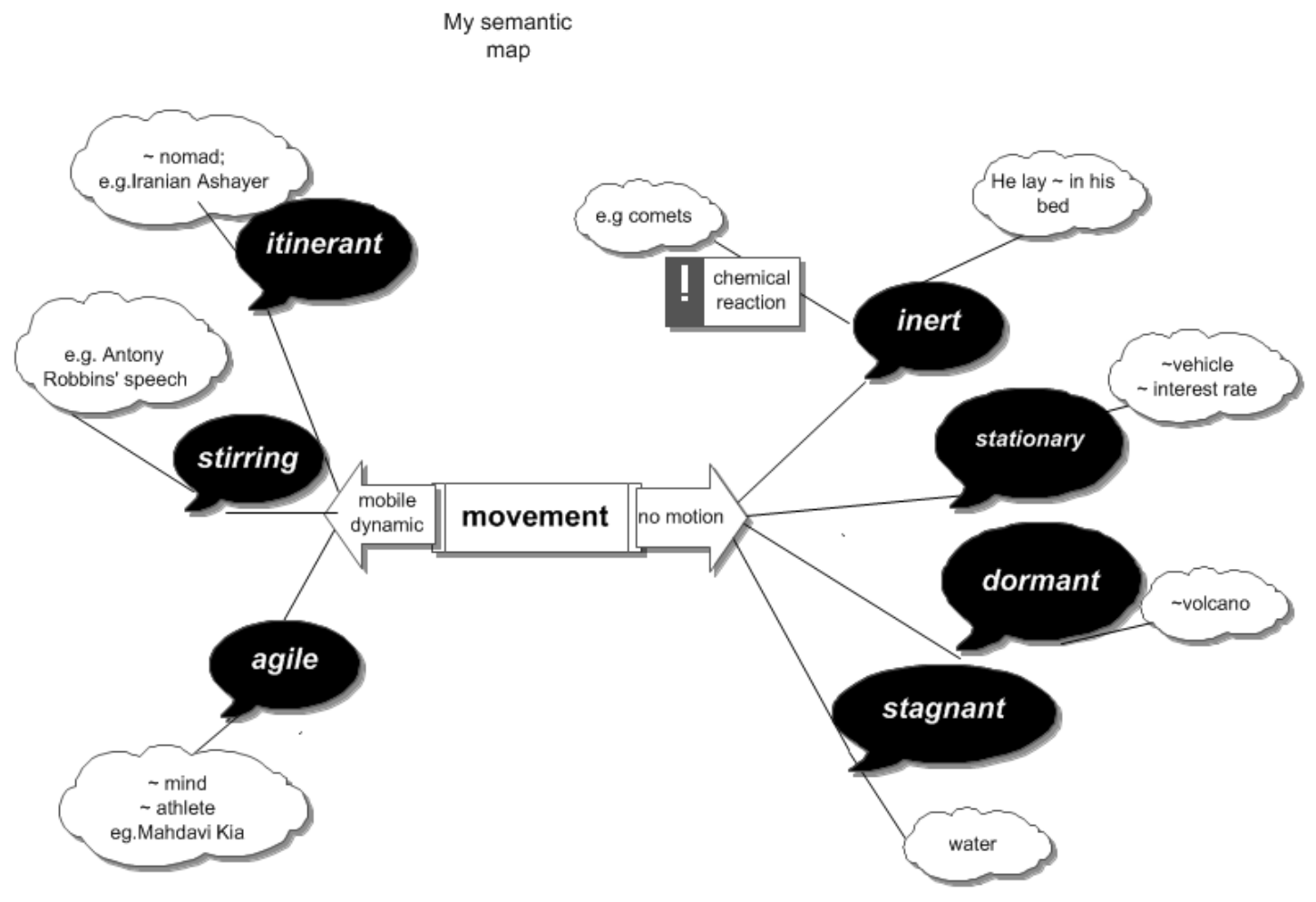

As for the application of metacognitive strategy, the students were required to create their own learning log in which they were taught: first, to write down a list of new words extracted from the book : second, make their own plan to describe and explain why and how they wanted to master them. Here is one sample indicating the metacognitive strategy use: 


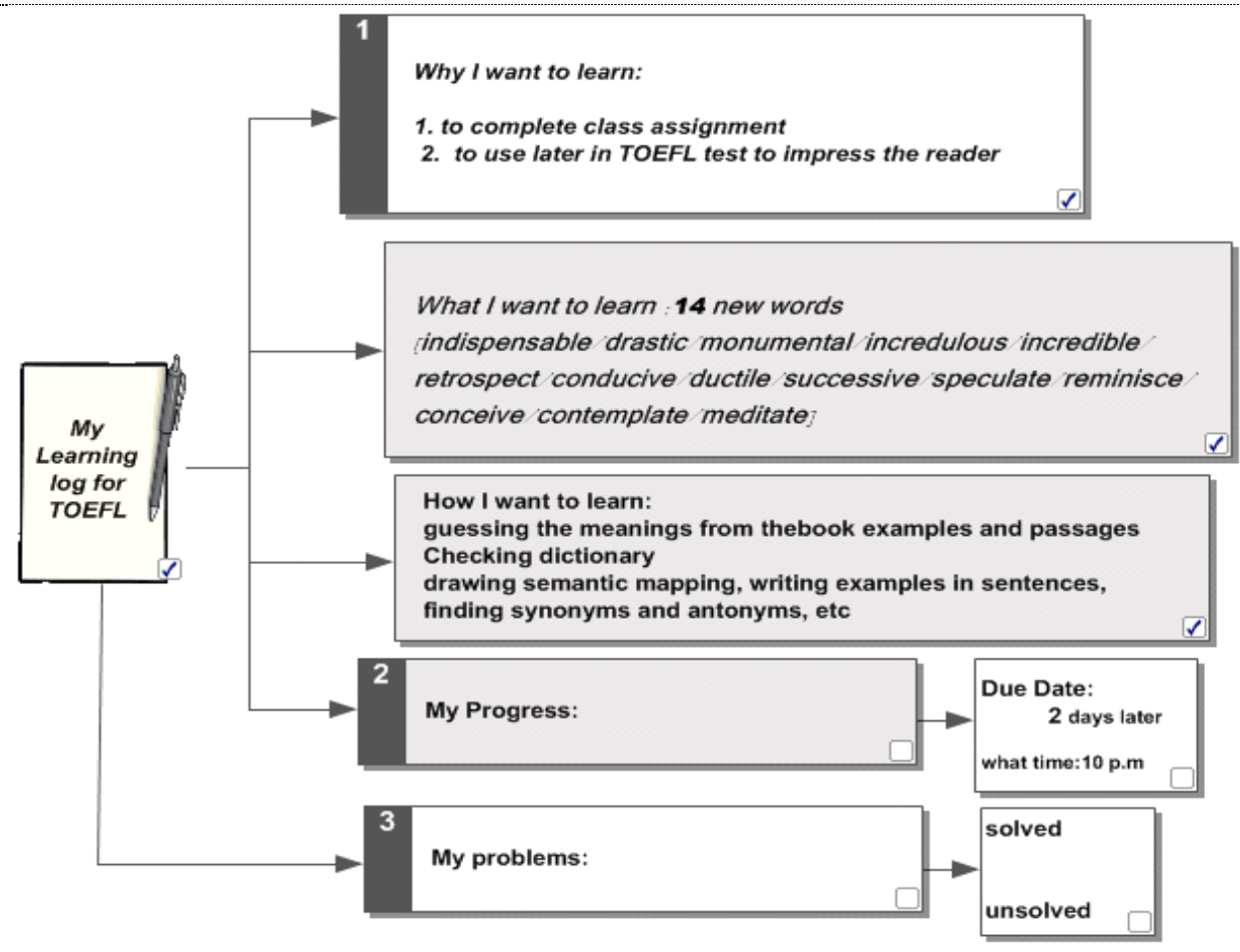

For the strategy of contextual guessing, in class the participants were required to figure out the meanings of the unfamiliar words highlighted in the reading passages of the book. They had to rely only on the passages to analyze and report the contextual clues that were helpful in guessing the meaning of the words. One sample work of contextualized guessing is presented here:

1. For twelve years Mann pleaded, argued, and lectured the government to improve the schools. He was a dedicated reformer. He even spent his vocations visiting schools around the country,...During his term as a superintendant, education made important strides in Massachusetts. He doubled teachers' salaries, and raised the minimum time children must attend school to six months a year. He improved the quality of teaching by... ( extracted from a passage in TOEFL WORD flash (Milada, 2005, p. 7)

Dedicated $=(\mathrm{I}$ think $)$ here it means: devoted

My reasons: because of the words: *even spent his vocations $\& *$ For twelve years

To make Strides $=($ I believe $)$ it means : to take forward steps

My reasons: because of the words $*$ doubled teachers' salaries, $\underline{* \text { raised the minimum time }, \text { and }}$ *improved.

With time interval of two weeks after treatment phase, the developed vocabulary achievement test (VAT) as a post-test, was administered to both groups in order to find out any difference in their vocabulary retention due to the strategybased intervention.

\section{Study design}

Due to the proposed research questions and the addition of the variable of gender as a moderator to the independent variable of the study (training 'deep' vocabulary learning strategies), this study required Factorial design in this experimental research. Regarding the reliability of the posttest, Cronbach alpha as an internal consistency estimate of reliability, based on split-half method, was computed for the vocabulary test. For the calculation of alpha coefficient the test items were split into two halves based on odd and even numbers to nullify the effects of unwanted factors such as tiredness of the test takers. The value for coefficient alpha $(\alpha)$ was .73 indicating satisfactory reliability. Considering the other main characteristics of the test, namely validity, first, all of the vocabulary items in the vocabulary achievement test (VAT) and the distracters were selected from the new lexical items of the course book. This strategy helped to increase the content validity of VAT. To check the criterion-related validity of the test, it was administered to a peer group of 30 EFL students along with Barron's TOEFL (version 1996), as a standardized test. In order to compute the validity of the posttest, the Pearson Product Moment correlation coefficient formula was used over the raw scores of the peer group in the proficiency test (Barron's TOEFL) and the developed posttest. The result showed .71 correlation coefficient $\left(\mathrm{r}_{\mathrm{xy}}=+0.71\right)$.

\subsection{Data Analysis}

To determine whether the prospected experimental and control groups met the criterion of equality of variances, an Ftest at the .05 level of probability was run over the mean scores (Table 1), gained from the performance of all four groups of the participants in the Barron's TOEFL test. 
Table 1. Descriptive Statistics of Barron's TOEFL

\begin{tabular}{|c|c|c|c|c|c|c|}
\hline GROUP & $n$ & $\mathrm{X}$ & $\mathrm{S}$ & S. E. & $\operatorname{Min} X$ & $\operatorname{Max} X$ \\
\hline Experimental ${ }_{\text {Female }}$ & 8 & 13.75 & 1.90 & 0.38 & 9.5 & 15 \\
\hline Experimental Male & 8 & 14.75 & 2.07 & 0.47 & 11 & 16 \\
\hline Control Female & 8 & 13.00 & 1.86 & 0.37 & 10.25 & 16 \\
\hline Control Male $_{\text {M }}$ & 8 & 13.75 & 1.72 & 0.34 & 13 & 15.5 \\
\hline
\end{tabular}

Subjecting the samples with 3/28 degrees of freedom to the test of homogeneity, it was found that the $F_{\text {crit. }}$ Value is not equal to or exceeded the $F_{\text {obs. }}$ Value $\left(F_{\text {crit. }}=2.95, F_{\text {obs. }}=2.12 ; 2.12<2.95\right)$. It meant that the difference between variances was not significant at the .05 level of probability, thus the variances fulfilled the condition of homogeneity; all the four groups were considered homogeneous in terms of their English language proficiency (Table2).

Table 2. One-way analysis of variance for gains of the proficiency test

\begin{tabular}{cccccc}
\hline Source & D.F. & Sum of Squares & Mean Squares & F Ratio & F Prob. \\
\hline Between Groups & 3 & 910.54 & 170.67 & 2.12 & 1.000 \\
Within Groups & 28 & 284.9 & 80.28 & & \\
\hline
\end{tabular}

$$
* \rho<.05
$$

In order to find any impact of training 'deep' vocabulary learning strategies (independent variable) on vocabulary retention of the participants in the experimental group and the role of the gender in influencing this impact, some statistical procedures were performed on the gained scores (see table 3 ) from the posttest .

Table 3. Descriptive Statistics of posttest

\begin{tabular}{llllllll}
\hline Group & $n$ & $\Sigma \mathrm{X}$ & $\overline{\mathrm{X}}$ & $\mathrm{S}$ & $\mathrm{S}^{2}$ & Min X & Max X \\
\hline Experimental $_{\text {Female }}$ & 8 & 270 & 33.75 & 2.93 & 8.60 & 39 & 25 \\
\hline Experimental $_{\text {Male }}$ & 8 & 228 & 28.50 & 2.7 & 7.29 & 35 & 17 \\
\hline Control Female $^{\text {Control }}$ & 8 & 162 & 20.25 & 3.07 & 9.48 & 29 & 14 \\
\hline
\end{tabular}

Following factorial design, to carry out analysis of variance procedures (ANOVA), at first, the gains for each group in posttest were calculated through SSPS. According to the gained results (table 4), an obvious progress in vocabulary retention is observed on behalf of experimental group $\left(\mathbf{X}_{\operatorname{Exp}}>\overline{\mathbf{X}}_{\text {Con }} ; 31.12>21.25\right)$, as F-ratio value proves this progress in vocabulary retention because of treatment $\left(\mathrm{F}_{\text {obs. }}>\mathrm{F}_{\text {crit. }} ; 18.07>4.20\right.$ at $\left.\rho=.05\right)$. Thus, the first null hypothesis of this study, which assumed that the explicit instruction of a 'deep' vocabulary learning strategy (semantic mapping) would not enhance vocabulary retention of Iranian EFL learners, was rejected at .05 level of probability.

Table 4. ANOVA for gains in vocabulary retention test related to treatment and gender

\begin{tabular}{lcclllll}
\hline Source & d.f. & S. S. & M. S. & F & Sig. & Eta. Square & d Power \\
\hline Between Groups & 1 & 12.582 & 612.582 & 40.41 & .000 & 75.8 & 1.000 \\
Treatment (A) & 1 & 206.94 & 206.94 & 18.07 & .002 & .73 & .881 \\
Gender (B) & 1 & & & & .004 & .42 & .000 \\
A X B & 1 & 117.6 & 117.6 & 9.75 & .09 & .013 & .072 \\
Within Groups & 28 & 49.92 & 49.92 & 4.16 & & & \\
Total & 31 & 336 & 12.00 & & & & \\
& & 750.50 & & & & & \\
\hline
\end{tabular}

$* \rho<.05$

Moreover, female participants' performance in experimental group shows more improvement in vocabulary retention (figure 1), compared to male participants' performance in experimental group $\left(\mathrm{F}_{\text {obs }}>\mathrm{F}_{\text {crit }} ; 9.75>4.20\right.$ at $\left.\rho=.05\right)$. The existence of some interaction $\left(\mathrm{F}_{\mathrm{obs}}=4.16\right.$ at $\left.\rho=.05\right)$ might attribute female participants' success to Factor A (treatment) and not to Factor B (gender). This possibility could question the impact of the moderator variable (gender) on the effectiveness of main factor of the research (treatment). However, this possibility is denied in safe grounds. First, interaction factor is not significance enough to make us suspicious of the main effects of moderator variable (gender) 
on vocabulary retention $\left(\mathrm{F}_{\text {obs. }}<\mathrm{F}_{\text {crit.; }} ; 4.16<4.20\right.$ at $\left.\rho=.05\right)$. Second, as it can be seen in figure 1, an obvious progress in vocabulary retention is observed on behalf of females experimental group, compared to that of females control group $\left(\overline{\mathbf{X}}_{\text {Female Exp }}>\overline{\mathbf{X}}_{\text {Female Con }} ; 33.7>20.25\right.$ ), as F-ratio value proves this impact of gender on the effectiveness of treatment for vocabulary retention $\left(\mathrm{F}_{\text {obs. }}>\mathrm{F}_{\text {crit. }} ; 9.75>4.20\right.$ at $\left.\rho=.05\right)$.

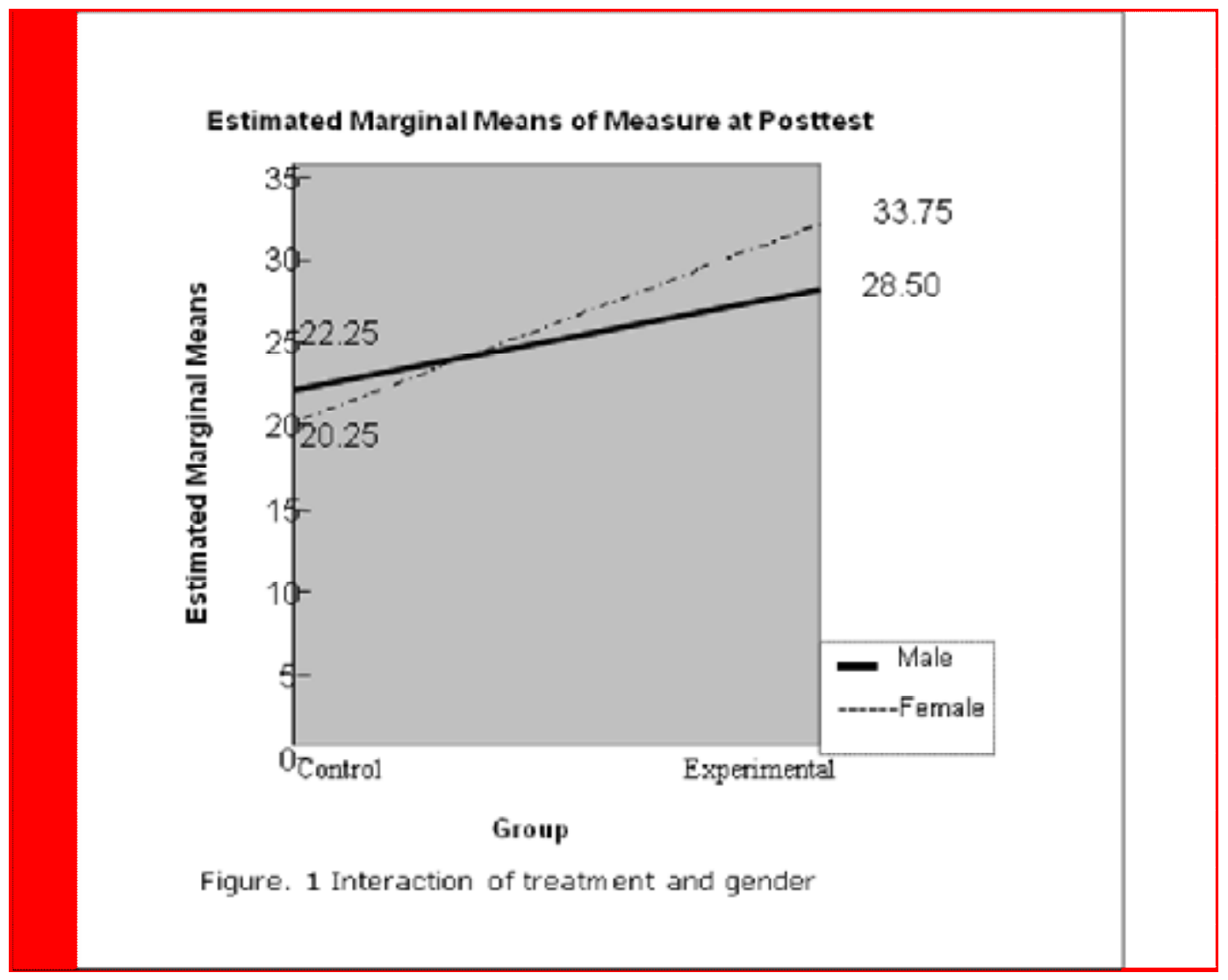

Thus, the second null hypothesis, which assumed that the variable of gender has no effect on the relationship between 'deep' vocabulary learning strategy instruction and vocabulary retention, was rejected at .05 level of probability.

\section{Discussion and implications of the results}

On the basis of the findings, we can claim that the effect of the treatment (explicit instruction of 'deep' vocabulary learning strategies as an independent variable) was significant in enhancement of vocabulary retention of experimental group, though female students welcomed strategy training in vocabulary learning more than male students did. These findings are promising in the light of the hypothesis of depth of processing (Craik et al. ,1972), according to which cognitively deep processing of a stimulus leads to better long-term memory retention. Moreover, these 'deep' vocabulary learning strategies, particularly semantic mapping, can be utilized as an effective tool (graphic organizer) not only for the task of vocabulary learning but also for reading and writing tasks in EFL classrooms; the necessity of activating background knowledge in students during semantic mapping procedures (Brainstorming) maintains the basics of schema theory that postulates, "new learning occurs either when adding to or adjusting already existing knowledge structures" (Stoller \& Grabe, 1993, p. 33).

However, there are some caveats to be considered before a large-scale implementation of teaching 'deep' vocabulary learning strategies in EFL classroom: first of all, to have an effective and fully-fledged implementation of training these strategies, teachers should be trained how to implement strategy instruction inside their classrooms as suggested in the existing research (see Oxford, 1990; O'Malley et al., 1990; Cohen \& Weaver, 1996). As a teacher implementing CALLA model in this study, I experienced that: first, teaching the cognitively demanding 'deep' strategies of vocabulary retention is pedagogically more demanding in terms of the required metalinguistic awareness and procedural knowledge inherent in strategy-based instruction, second, students participating in this study showed reluctance in applying Keyword method.; for them simply finding phonetically L1 equivalents for new words was subject to intensive mental processing.

In addition, the significance attached to the high scores of the students on the receptive test of this study as post-test which was administered immediately two weeks after the treatment, statistically can not indicate long-term retention of vocabulary. Since, as Kudo (1999) believes, a clear-cut distinction or border between short-term and long-term retention for vocabulary retention as process-oriented mental procedure can not be firmly established, and some weeks later most of newly-learnt words may be beyond recall.

Another point to be taken into account before generalizing the findings of this paper is the small sample size (32 students) which can not represent the whole population of Iranian EFL learners. Particularly the cultural and linguistic background of the participants might influence any outcome of training these strategies. In this study all the students 
were Azri native speakers with Azari cultural background who had already experienced learning a second language of Persian.. As Nielson (2003) states: "certain cultural groups are likely to have quite different opinions regarding what VLS [vocabulary learning strategies] they consider useful, which may result in resistance to learning some types of alternative vocabulary learning strategies" (p.12).

\section{Conclusion}

The findings of this research shed light over the existing uncertainty in the relevant research literature (e.g. Kudo, 1999) about the usefulness of teaching 'deep' vocabulary strategies; in spite of 'deep' mental processing required in the application of these strategies the explicit instruction of 'deep' vocabulary learning strategies, proved to be effective in improving vocabulary retention of Iranian EFL students. Another finding of this study, regarding the higher degree of receptiveness in female students to the explicit strategy instruction and use, is consistent with the reported research (see Erhman \& Oxford, 1990; Kaylani, 1996; Oxford, 1994; Schueller, 2004) and supports the emerging theory which proposes that females employ more learning strategies or employ strategies more effectively.

\section{References}

Brown, J. D. (1996). Testing in language programs. NJ: Prentice-Hall Regents.

Chamot, A. U \& O' Malley, J. M. (1994). Language learner and learning strategies. In N.C. Ellis (ed.), Implicit and explicit learning of languages (pp. 371-392). London: Academic.

Coady, J. (1997). L2 vocabulary acquisition through extensive reading. In J. Coady \& T. Huckin (Eds.), Second language vocabulary acquisition (pp. 225-237). Cambridge: Cambridge University Press.

Cohen, A., \& Aphek,E. (1980). Retention of second language vocabulary over time: investigating the role of mnemonic association. System, 8, 221-235.

Cohen, A. D., Weaver, S.J (1996). The impact of strategies-based instruction on speaking a foreign language. University of Minnesota, Minneapolis: CARLA Working Paper Series 4. Retrieved on July 19, 2006, from the ERIC data base.

Craik, F. \& Lockhart, R. (1972). Levels of processing: A framework for memory research. Journal of Verbal learning and Verbal Behavior, 11, 671-684.

Ehrman, M. \&. Oxford, R. (1990). Adult language learning styles and strategies in an intensive training setting. Modern Language Journal, 74, 311.

Ellis, R. (1995). Modified oral input and the acquisition of word meaning. Applied Linguistics, 16, 409-441.

Gu, P. Y. (2003).Vocabulary Learning in a Second Language: Person, task, context and strategies. TESL-E, 7, 2,2.

Haynes, M. (1993). Patterns and perils of guessing in second language reading. In T. Huckin, M. Haynes, M., \& J. Coady (Eds.), Second language reading and vocabulary learning (pp. 46-64). Norwood, N.J.: Ablex.

Hunt, A., Beglar, D. (2005). A framework for developing EFL reading vocabulary. Reading in a Foreign Language, 17, $11-21$

Kaylani, C. (1996). The Influence of gender and motivation on EFL learning strategy use in Jordan. In R. L. Oxford (Ed.), Language learning strategies around the world: Cross-cultural perspectives (pp. 75-88). Honolulu: Second Language Teaching \& Curriculum Center, University of Hawaii.

Kudo, Y. (1999). L2 vocabulary learning strategies. Honolulu: University of Hawai'i, Second Language Teaching \& Curriculum Center.

Milada, B. (2005). TOEFL word flash. London: Peterson's Thomson Learning.

Nielsen, B. (2003). A review of research into vocabulary learning and acquisition. Retrieved on July 19, 2006, from http://www.kushiro-ct.ac.jp/library/kiyo/kiyo36/Brian.pdf.

O' Malley, J. M., Chamot, A. U. (1990). Learning strategies in second language acquisition. Cambridge: Cambridge University Press.

Oxford, R. (1990). Language learning strategies: What every teacher should know. New York: Newbury.

Oxford, R. (1994). Language learning strategies. Retrieved on Nov 19, 2006, from the Eric database.

Oxford, R., Nyikos, M. (1989). Variables affecting choice of language learning strategies by university students. The Modern Language Journal, 73, 3, 291.

Rasekh, Z, E., Ranjbary, R. (2003). Metacognitive strategy training for vocabulary learning. RELC Journal, 30, 2, 6.

Schmitt, N. (1997).Vocabulary learning strategies. In N. Schmitt \& M.acCarthy (Eds.), Vocabulary description, acquisition and pedagogy (p. 199-227). Cambridge: Cambridge University Press.

Schueller, J. (2004). Gender and foreign language reading comprehension: The effects of strategy training. In C. Brantmeier (Ed.), Adult foreign language reading: Theory, research and implications (pp.45-64). NJ: Southern Journal of Linguistics. 
Segler, T. (2001). Second language vocabulary acquisition and learning Strategies in ICALL Environments. Retrieved on April 12, 2006, from"http://www.dai.ed.ac.uk/homes/newprop.pdf.

Stoller, F \& Grabe, W. (1993). Implications for L2 vocabulary acquisition and instruction from L1 vocabulary research. In T, Huckin, M, Haynes \& J, Coady (Eds.), Second language reading and vocabulary learning (pp. 24-39). New Jersey: Ablex Publishing Corporation.

Zeid M.A. (1995). Semantic mapping in communicative language learning. Reading Forum, 33(3),6. 